\title{
HIV Prevalence Among Blood Donors in a Blood Bank in Curitiba (Brazil)
}

José Luiz Andrade Neto, Vitor Last Pintarelli,
Paulo Cesar Zimmermann Felchner,
Rodrigo Leite de Morais and Fabíola Lie Nishimoto

\author{
Federal University of Paraná, Curitiba, PR, Brazil
}

\begin{abstract}
There still is no cure for the acquired immunodeficiency syndrome (AIDS). Its etiologic agent is the human immunodeficiency virus (HIV), and transmission occurs through sexual relationships, contacts with blood, and vertically (mother to child). In this study, we sought to determine the prevalence of HIV among blood donors at a blood bank in Curitiba. We studied 213,666 blood donations made from March 1, 1992, to April 25, 1999. Each potential blood donor first answered a questionnaire, submitted to a clinical examination, and filled out a self-exclusion card. Blood was collected and analyzed only from the candidates approved by the first two criteria. Two tests were used to detect HIV: ELISA for screening, and Western-Blot for confirmation. The results were analyzed statistically by determining the $95 \%$ confidence interval. Of the total number of donors, 156,942 were men, and 56,724 were women. There were 319 cases of HIV infection ( 244 men, 75 women). There were no significant differences between genders, or among the different age groups, or between first-donation and repeated-donation donors. There was a significant predominance of HIV infection among single individuals compared to married, widowed, and other individuals. The same occurred among married and divorced individuals compared to widowed subjects. The prevalence of HIV among blood donors was $0.149 \%(0.155 \%$ among men and $\mathbf{0 . 1 3 2 \%}$ among women). The frequency of HIV was statistically identical among new blood donors and repeat donors. A large number of HIV-infected married women was also observed. Key Words: AIDS, blood donor, HIV.
\end{abstract}

The acquired immunodeficiency syndrome (AIDS) was discovered in 1981, in the United States of America, following the observation of male homosexual patients with manifestations of acquired immunodeficiency, such as opportunistic infections and Kaposi's sarcoma. AIDS will be one of the main challenges for medicine in the $21^{\text {st }}$ century [1-4]. With its advent, many ancient diseases, such as tuberculosis, which were already considered eradicated in many places on Earth, re-emerged alarmingly. Other diseases, which, were almost unknown or considered

Received on 15 March 2001; revised 23 November 2001.

Address for correspondence: Dr. Vitor Last Pintarelli. Rua Gabirobas, 12 casa 20 Uberaba - Curitiba - Paraná, Zip code: 81560-150. Telephone number: (41)-369-3419. E-mail: vitorpintarelli@hotmail.com

The Brazilian Journal of Infectious Diseases 2002;6(1):15-21 (C) 2002 by The Brazilian Journal of Infectious Diseases and Contexto Publishing. All rights reserved.

$1413-8670$ to be rare conditions restricted to some groups of highly debilitated patients before the discovery of AIDS, have become routine findings in hospitals all over the world.

The cure for AIDS remains unknown, but its transmission mechanisms were described in the first years after the discovery of the etiologic agent, the human immunodeficiency virus (HIV), which was first isolated in 1983 [5-8].

AIDS can be transmitted from person to person by sexual relationships (homosexual or heterosexual), blood transfusions (with total blood or derived products, organ and tissue transplantation from contaminated people, or accidents that expose a healthy person to contaminated blood) and vertically from a mother infected with HIV to her child during pregnancy, delivery or breast feeding [9-13]. Since there is no curative treatment for AIDS, but the ways by which contamination occurs are already known, emphasis has been placed on the importance of 
preventing HIV transmission. Since the 1980s many different preventive approaches have been used according to the type of contamination to be avoided.

Specifically, in hospitals, blood banks, and other health settings, one of the main efforts in the fight against HIV transmission consists of rigorous control of blood products used for transfusions. This has been done by analyzing biological and behavioral characteristics of the candidates for blood donation and examining the collected blood, which intends to identify not only HIV infection, but also other pathologic conditions that could temporarily or permanently impair the blood donation. As a result, it is calculated that the risk of acquiring the AIDS virus through a blood transfusion is about 2 in 1 million [14] or even lower [15].

\section{Objectives}

This study set out to determine the prevalence of the human immunodeficiency virus among blood donors at a blood bank in Curitiba (Brazil) by analyzing the distribution of these donors according to gender, age, and marital status, and by determining whether a donation was being made for the first time or was being repeated.

\section{Material and Methods}

We analyzed 213,666 blood donations made at a blood bank in Curitiba, from March 1, 1992, to April 25,1999 . All of the candidates for blood donation previously answered a questionnaire in the form of an interview, were submitted to a clinical examination and filled out a self-exclusion card. Blood was collected for analysis only from the donors approved in the steps involving clinical screening and response to the questionnaire. The self-exclusion cards were filled out by all donors and were read only after the donation and after the serologic exams described below.

In the clinical screening, the candidates for donation were identified according to personal data and, subsequently, were evaluated according to vital and biometric data such as weight, height, arterial pressure, pulse, and body temperature. A blood sample was also obtained for immediatedetermination of globularvolumeand hemoglobin.
The donors approved after the hematological prescreening were subsequently asked to reply to a questionnaire containing 30 questions about their health during the preceding months, and about their medical history. They were asked to report about their personal histories of diseases such as leprosy, tuberculosis, trypanosomiasis, malaria, cancer, hepatitis, diabetes, arterial hypertension, allergies, syphilis, other sexually transmitted diseases, and AIDS. The subjects were also questioned about symptoms frequently found in patients with infectious diseases and about personal circumstances which might be related to a higher probability of acquisition of infectious diseases such as drug-addiction, sexual behavior, blood transfusions, and any history of surgery.

After approval in the basis of questionnaire mentioned above, the next step before the blood donation consisted of filling out an anonymous selfexclusion card, in which the donors were asked if there was any possibility that they might be infected with HIV. Such cards were identified only and by a code that prevented other people from identifying the donor, and the cards were filed in locked boxes that were only opened in the absence of the donor. All subjects approved in the hematological prescreening and in the questionnaire were submitted to blood collection, and their blood was subsequently submitted for serologic laboratory analysis. The blood donations from those who replied affirmatively on the self-exclusion cards, were automatically discarded according to the rules routinely adopted by the blood bank for such cases, even if their exams did not identify any obstacle to donation.

For each blood collection, the volume taken was specifically determined for each case, according to the biometric characteristics of the donor. The blood obtained was then submitted to routine tests. With respect to infectious diseases with a risk of transmission by blood transfusion, serologic tests were performed to detect contamination by the etiologic pathogens of Chagas disease, hepatitis B and C, syphilis, AIDS, and infection by the HTLV.

The tests used to detect HIV infection were batteries headed by the ELISA [16-19] test, which was used as a screening method for positive results. After a first 
ELISA-positive result, donors were asked to give a new blood sample which was analyzed again by the same method. When a positive result persisted, the sample was submitted to Western-Blot [19] and to testing p24 antigen research [16,20,23]. HIV infection was considered positive in the cases when WesternBlot or p24 antigen detection gave positive results.

Most of the donors studied were 18 to 60 years old. The only subjects outside of this range were donors who collected blood for self-transfusion for elective surgical proceedures.

The results of serologic tests for HIV detection were analyzed according to personal characteristics of each donor, such as gender, age group, legal status, and whether the donation was their first or was repeated. The age groups were considered in the present study. Group 1 consisted of individuals $<18$ years, Group 2 included individuals aged 18 to 25 years, Group 3 through 9 were in 5 year progressions, Group 10 consisted of individuals $>60$ years. In regard to marital status, five possibilities were considered according to the donor's declaration: single, married, divorced, widowed, and others (most were reported as having informal unions).

Data about the blood donors studied in the present investigation were obtained from the computer files of the blood bank in the form of summarized tables. They were analyzed statistically with the confidence interval test, with the level of significance set at $5 \%$ in all calculations.

\section{Results}

Of a total of 213,666 blood donors studied, 156,942 were male and 56,724 were female. Among them, 319 had positive serologic tests for HIV infection (244 men and 75 women). The analysis of these numbers, with a 95\% confidence limit, did not demonstrate a significant difference between genders.

In relation to age groups, this study considered both the total results obtained with this criterion and the age groups of each gender (Table 1). The age group that presented the highest number of donors was Group 2 (18 to 25 years old) for both genders. This was also the group with the greatest number of cases of HIV infection. However, there were no statistically significant differences among the age groups of men and the total ones. Among women donors, Group 2 (18 to 25 years) and Group 4-7 (31 to 50 years) presented the highest prevalence of HIV infection and were statistically different from all the other age groups. Female donors in Group 1 ( $<18$ years) showed similar results to those of women $>51$ with the lowest prevalence of HIV infection observed among these two groups. Women in Group 3 (26 to 30 years) had an intermediate prevalence of HIV infection.

Concerning marital status (Table 2), most donors declared they were married (133,253 people), followed by single $(66,109)$. The single category had the second highest prevalence of HIV among the marital status groups (155 cases, or $0,18 \%$ positivity); while the divorced donors had a prevalence of $0.22 \%$. Among male donors, there were statistically significant differences between the following groups: single/ married, single/widower, single/other, married/widower, divorced/widower, widower/other. The other pairs did not present any differences. Among female donors, the pairs that were statistically different were: single/widow, single/other, married/widow, married/other; there were no differences between other pairs.

The item number of blood donations was analyzed in terms of this being a first time or a repeated blood donation (Table 3). Most donors were donating blood for the first time (163,094 cases; 118,176 men and 44,918 women), while 50,572 (38,766 men and 11,806 women) were repeating a donation. A total of 262 cases of HIV infection were detected among firstdonation donors (198 men and 64 women), and 57 cases were detected among repeated-donation donors (46 men and 11 women). Statistical analysis did not show any difference in HIV prevalence between firstdonation and repeated-donation donors.

\section{Discussion}

Information is scarce about the prevalence of pathogens such as HBV, HCV, and HIV among volunteer blood donors in Brazil, but the available studies demonstrate a trend of reduction in the risk of 
Table 1. HIV prevalence and age groups

\begin{tabular}{|c|c|c|c|c|c|c|}
\hline \multirow[t]{2}{*}{ Age groups } & \multicolumn{2}{|c|}{ Male } & \multicolumn{2}{|c|}{ Female } & \multicolumn{2}{|c|}{ Total (mal + fem) } \\
\hline & Donors & HIV & Donors & HIV & Donors & Total HIV \\
\hline$<18$ years & 136 & 1 & 41 & 0 & 177 & 1 \\
\hline $18-25$ years & 51,670 & 74 & 16,894 & 32 & 68,564 & 106 \\
\hline $26-30$ years & 30,104 & 57 & 9,943 & 6 & 40,047 & 63 \\
\hline $31-35$ years & 24,770 & 44 & 9,187 & 14 & 33,957 & 58 \\
\hline $36-40$ years & 19,354 & 29 & 8,025 & 9 & 27,379 & 38 \\
\hline $41-45$ years & 14,152 & 20 & 5,907 & 8 & 20,059 & 28 \\
\hline $46-50$ years & 9,288 & 11 & 3,734 & 5 & 13,022 & 16 \\
\hline $51-55$ years & 5,064 & 6 & 2,034 & 1 & 7,098 & 7 \\
\hline $55-60$ years & 2,313 & 2 & 930 & 0 & 3,243 & 2 \\
\hline$>60$ years & 91 & 0 & 29 & 0 & 120 & 0 \\
\hline Total & 156,942 & 244 & 56,724 & 75 & 213,666 & 319 \\
\hline
\end{tabular}

Number of cases of seropositivity among donors, according to gender and age group.

Table 2. HIV prevalence and legal status

\begin{tabular}{|c|c|c|c|c|c|c|}
\hline \multirow{2}{*}{$\begin{array}{l}\text { Legal } \\
\text { status }\end{array}$} & \multicolumn{2}{|c|}{ Male } & \multicolumn{2}{|c|}{ Female } & \multicolumn{2}{|c|}{ Total (mal + fem) } \\
\hline & Donors & HIV & Donors & HIV & Donors & Total HIV \\
\hline Single & 60,745 & 118 & 22,279 & 37 & 8,3024 & 155 \\
\hline Married & 90,286 & 112 & 28,964 & 33 & 119,250 & 145 \\
\hline Divorced & 4,412 & 13 & 3,633 & 5 & 8,045 & 18 \\
\hline Widowed & 590 & 0 & 1,560 & 0 & 2,150 & 0 \\
\hline Other & 909 & 1 & 288 & 0 & 1,197 & 1 \\
\hline Total & 156,942 & 244 & 56,724 & 75 & 213,666 & 319 \\
\hline
\end{tabular}

Number of cases of seropositivity among donors, according to gender and legal status.

Table 3. HIV prevalence and first-donation and repeating-donation donors

\begin{tabular}{|c|c|c|c|c|c|c|}
\hline \multirow{2}{*}{$\begin{array}{l}\text { Number of } \\
\text { donations }\end{array}$} & \multicolumn{2}{|c|}{ Male } & \multicolumn{2}{|c|}{ Female } & \multicolumn{2}{|c|}{ Total (mal + fem) } \\
\hline & Donors & HIV & Donors & $\overline{\text { HIV }}$ & Donors & Total HIV \\
\hline $1^{\text {st }}$ donation & 118,176 & 198 & 44,918 & 64 & 163,094 & 262 \\
\hline Repetition & 38,766 & 46 & 11,806 & 11 & 50,572 & 57 \\
\hline Total & 156,942 & 244 & 56,724 & 75 & 213,666 & 319 \\
\hline
\end{tabular}


acquiring this retrovirus through blood transfusions during the 1990 decade [22-23]. In spite of the demonstration that HIV prevalence has increased among low risk populations throughout the world, the epidemiologic profile of HIV-infected blood donors has not been determined in Brazil [24].

In the present study, no significant differences in HIV prevalence were observed between men and women, or between age groups. However, it is known that in the Brazilian population, in general, and in the populations of Paraná State and of the city of Curitiba, the prevalence of seropositivity is significantly higher among males than females, and is significantly higher among people aged 20 to 40 years of both sexes [2528]. This suggests that the blood donors considered in the present study do not represent a pure population sample, but a group of people selected by the defined criteria mentioned above. These criteria, presumably, were efficient in excluding from blood donation people with a higher chance of being HIV carriers, even though asymptomatic, or included in the immunologic window.

In relation to age groups, there were no statistically significant differences in HIV infection among donors as a whole or among male groups. However, there were significant differences in the prevalence of HIV infection among female age groups, with three distinct patterns being detected: low prevalence $(<18$ and $>$ 50 years old), intermediate prevalence $(26-30$ years old) and high prevalence (18-25 and 31-50 years old). According to recent articles [25-28], women constitute the group of seropositive individuals that shows the greatest increase in the prevalence of HIV infection, especially married women or women who maintain a stable and monogamous relationship. The same studies show that these women are frequently infected by their partners, who commonly have sexual relations with other women (HIV carriers) without their partner's knowledge. The partner, considering her relationship to be monogamous, does not use protective methods to avoid contamination. Thus, by comparing the data obtained in previous studies with the numbers reported here, it is possible to assume that many of the seropositive women detected are exposed to conjugal contamination and, because they are unaware of their risk status, they are not excluded from blood donation on the basis of their replies to the bio-behavioral questionnaire or of the self-excluding card.

With respect to the marital status declared by the blood donors, it is important to emphasize that the answers given many times did not correspond to the information present in their documents, but to the concept that each one had of his/her own condition. Many articles have demonstrated that most cases of HIV transmission occur through sexual relationships in both genders [25-27,29]. Among male donors, there were statistically significant differences between the pairs: single/married, single/widower, divorced/widower. Possibly, these differences can be explained by behavioral characteristics mainly related to single and divorced individuals, who have a greater variety of sexual partners and, therefore, are more exposed to the possibility of contamination. Among female donors, there were statistically significant differences between the pairs: single/widow, single/others, married/widow, and married/others. Hence, HIV prevalence among the single, married, and divorced women considered in this study was statistically the same and always higher than that observed among widows and women with a different legal status. Thus, the risk factor for HIV contamination among single, married and divorced women may be sexual activity, considering that married women constitute the epidemiological group with the greatest increase in HIV carriers due to the large number of women who are unknowingly contaminated by their husbands. Single and divorced women, who often present a risk behavior with respect to sexual activity, have higher chances of acquiring HIV than widows and others. Regarding the risk of HIV acquisition, the marital factor itself cannot be considered a protective or an exposure factor. More important than the condition declared by every donor is his/her awareness and behavior in the ways of preventing HIV transmission.

When the prevalence of seropositivity was compared between first-donation and repeateddonation donors, no significant difference was observed between them. The literature [30-32], however, shows that repeated donors usually present a lower prevalence of HIV than first-donation donors. This is frequently explained by the fact that people who regularly donate blood usually have a profile of low-risk of HIV 
contamination because they were selected many times and constitute a group in which, as previously demonstrated, the infection rates of agents like HIV, $\mathrm{HCV}$, and HTLV I and II are lower than those found in sporadic donors, even with adjustments for demographic characteristics [33]. Thus, the statistical equality of HIV prevalence among first-donation donors and repeated-donation donors observed in the present study can be explained by circumstances such as high infectivity of AIDS in the study population, causing a large number of people to acquire HIV infection after a first blood donation and then to be prevented from donating again; use of blood donation as a means to obtain HIV testing by people with a high risk of HIV contamination; existence of a high prevalence of people inside the immunological window who offer to donate blood and are not excluded on the basis of clinical criteria or bio-behavioral and selfexcluding data; or lower efficacy of older serologic tests, which may have failed to detect HIV on the occasion of first donation by contaminated individuals.

Hence, it can be seen that the profile of HIV carriers accepted for blood donation by the screening criteria described above is very distinct from that observed in individuals who are also infected with HIV but belong to an unselected population sample. In the second case, most of the individuals belong to the male gender, are included in young age groups (18 to 40 years old), and present some risk factor for HIV contamination that can be fairly easily identified, mainly risky sexual behavior or illicit drug use. The individuals accepted for blood donation by the screening criteria, but whose blood samples were found to be contaminated with HIV, presented a distinct profile. There were no significant differences between genders or among age groups (except in the case of women, in which donors aged 18 to 50 years presented a higher prevalence than the other age groups), or between first-donation and the repeated-donation donors.

Among blood donors, marital status cannot be considered an exposure or protection factor with respect to HIV contagion, because the most important factor is the behavior of every person and the preventive measures individually adopted. A higher prevalence of
HIV infection was detected among single and divorced individuals who, according to common habits observed in the Brazilian population, demonstrate higher risk sexual behaviors than married and widowed individuals. However, the prevalence of HIV infection was higher among married individuals than among widowed individuals (among women, it was equivalent to that observed among single and divorced individuals); a fact confirming that marital status cannot be considered a risk factor for HIV contagion.

\section{Conclusions}

We observed that the overall HIV prevalence among the blood donors at the blood bank being studied was $0.149 \%$. The prevalence was $0.155 \%$ among male donors and $0.132 \%$ among female donors.

With respect to HIV prevalence according to age, we concluded that no age group was more affected than others, as shown by the absence of significant differences in prevalence among groups, even when the data were evaluated for all donors as a whole or for male donors alone. Regarding female donors, we observed a higher prevalence of HIV among women between 18 and 50 years old.

We also concluded that there were no significant differences in HIV prevalence between first-donation donors and repeated-donation donors.

Regarding marital status, HIV prevalence was found to be significantly higher among single and divorced individuals than among married or widowed individuals. However, among women, there was a greater proportion of married than widowed HIV carriers.

\section{References}

1. Gottlieb M.S., Schroff R., Schanker H.M., et al. Pneumocytis carinii pneumonia and mucosal candidiasis in previously healthy homosexual men: evidence of a new acquired immuno-deficiency. N Engl J Med 1981;305:1425.

2. Centers for Disease Control. Kaposi's sarcoma Pneumocystis pneumonia among homosexual men. MMWR 1981;30:305.

3. Centers for Disease Control. Pneumocystis pneumonia. MMWR 1981:250. 
4. Masur H., Michelis M.A., Onorado I., et al. An outbreak of community-acquired pneumocystis carinii pneumonia: initial manifestation of celular immune disfunction. N Engl J Med, 1981;305:1431-8.

5. Barré-Sinoussi F., Chermann J.C., Rey F., et al. Isolation of a T-lymphotrofic retrovirus from a patient at risk for acquired immune deficiency syndrome. Science 1983;220:868-71.

6. Gallo R.C., Salahuddin S.Z., Popovic M., et al. Frequent detection and isolation of cytopathic retroviruses (HTLV-III) from patients with AIDS and at risk for AIDS. Science 1984;224:500-3.

7. Popovic M., Sarngadharan M.G., Read E., et al. Detection, isolation and continuous production of cytopathic retroviruses (HTLV-III) from patients with AIDS and pre-AIDS. Science 1984;224:497-500.

8. Levy J.A., Hoffman A.D., Kramer S.M., et al. Isolation of lymphocytopathic retroviruses from San Francisco patients with AIDS. Science 1984;225:840.

9. Ho D.D., Schooley R.T., Rota T.R., et al. HTLV-III in the semen and blood of a healthy homosexual man. Science 1984;226:451.

10. Thiry L., Sprecher-Goldberger S., Jonckheer, et al. Isolation of AIDS virus from cell-free breast milk of three healthy virus carriers. Lancet 1985;2:891.

11. Vogt M.W., Witt D.J., Craven D.E., et al. Isolation of HTLVII/LAV from cervical secretions of women at risk for AIDS. Lancet 1986; 1:525.

12. Wofsy C.B., Cohen J.B., Hauer L.B, et al. Isolation of AIDS associated retrovirus from genital secretion of women with antibodies to the virus. Lancet 1986;1:527.

13. Zagury D., Bernard J., Leibowitch J., et al. HTLV-III in cells cultured from semen of two patients with AIDS related complex and health homosexual men at risk for AIDS. Science 1984;226:449.

14. Schreiber B.G., et al. Retrovirus epidemiology donor study. N Engl J Med 1996; 334:1685-90.

15. Regan F. A. M., Hewitt P., Barbara J.A.J., Contreras M. Prospective investigation of transfusion transmited infection in recipients of over 20,000 units of blood. BMJ 2000;320:403-6.

16. Mazza C.C. Epidemiologia da SIDA em homossexuais promíscuos. Prevalência de Ac LAV/HLTV-III em travestis na cidade de São Paulo. São Paulo,1986. 68p. Dissertação - Tese de Mestrado - Faculdade de Medicina da Universidade de São Paulo.

17. Granato C. Estudo seqüencial de infecção pelo vírus da imunodeficiência adquirida em grupos selecionados da cidade de Santos, São Paulo, Brasil, 1987 a 1990. São Paulo, 1991. 60p. Dissertação (Mestrado). Faculdade de Medicina da Universidade de São Paulo.

18. Medenhall C.L., Roselle G.A., Grossman C.J., et al. False positive tests for HTLV-III antibodies in alcoholic patients with hepatitis. N Engl J Med 1986; 314:921-2.
19. Morgan J., Tate R., Farr A.D., et al. Potential source of error in HTLV-III antibody testing. Lancet 1985;2:873-7.

20. Gallo R.C., Shaw G.M., Markham P.D. The etiology of AIDS. In: De Vita Jr, Hellman S., Rosemberg S.A. AIDS - etiology, dianostic, treatment and prevention. Philadelphia: Lippincott, 1985.

21. Fischinger P.J., Bolognesi D.P. Prospects for diagnostic tests, intervention, and vaccine development in AIDS. In: De Vita Jr, Hellman S., Rosemberg S.A. AIDS - etiology, dianosis, treatment and prevention. Philadelphia: Lippincott, 1985.

22. Treitinger A., Spada C., Ferreira L.A.P.,et al. Hepatitis B and hepatitis $C$ prevalence among blood donors and HIV-1 infected patients in Florianópolis - Brazil. Braz J Infect Dis 2000;4(4): 192-6.

23. Kupek E.J. The reduction of HIV transfusion risk in southern Brazil in the 1990s. Tranfus Med 2001;11(2):75-8.

24. Kupek E.J. HIV seroprevalence among blood donors in southern Brazil in the decade of 1990. Braz J Infect Dis 2000;4(5):217-25.

25. Ministério da Saúde, Divisão Nacional de Doenças Sexualmente Transmissíveis / AIDS. AIDS Boletim Epidemiológico 1999;1(1).

26. Ministério da Saúde, Coordenação Nacional de Doenças Sexualmente Transmissíveis / AIDS. Número de casos de AIDS por sexo e idade, no período 1992-1999. Available in: www.datasus.gov.br Accessed on Oct. $24^{\text {th }} 1999$.

27. Szwarewald C.L, Bastos F.I.B., Castilho E.A. The dynamics of the AIDS epidemic in Brazil: a space-time analysis in the period 1987-1995. BJID 1998;2(4):175-86.

28. Vermelho L. Women with AIDS: transmission and prevention strategies. Int Conf AIDS 1998;12:440-1.

29. Campos M.A. Circumstances of diagnoses of HIV infection in Belo Horizonte, Brazil. Int Conf AIDS 1998; $12: 818-9$.

30. GlíuckD., Koerner K., Caspari G., ElbertG., Gaus W., Gríassmann W., Hesse R., Holzberger G., Sternberger J., Vornwald A., et al. Epidemiology of HIV in blood donors in West Germany. Dtsch Med Wochenschr 1988;113(36): 1383-9.

31. Aymard J.P., Janot C., Contal P., Linel C., Monange G., Streiff F. Epidemiologic study of HIV serology in blood donors from 5 departments in northeastern France. Ver Fr Transfus Hemobiol 1989;32 (6):421-9.

32. Petersen L.R., Doll L.S., White C.R., Johnson E., Williams A. and The HIV Blood Donor Study Group. Heterosexually acquired human immunodeficiency virus infection and the United States blood supply: considerations for screening of potencial blood donors. Transfusion 1993;33 (7):552-7.

33. Glynn S.A., Schreiber G.B., Busch, M.P., Kleinman S.H., Williams A.E., Nass C.C., Ownby H.E., Smith J.W. Demographic characteristics, unreported risk behaviors, and the prevalence and incidence of viral infections: a comparison of apheresis and whole-blood donors. Transfusion 1998;38:350-8. 